\title{
Reliability Ananlysis of Cooling System of Diesel Engine
}

\author{
Dhananjay R Dolas ${ }^{*}$, Sudhir Deshmukh \\ MGM's Jawaharlal Nehru Engineering College, India
}

Copyright (C 2015 Horizon Research Publishing All rights reserved.

\begin{abstract}
Diesel engine is use in various field for the different application, the performance of engine is depends on the engine systems \& components. The cooling system is one of the important systems for diesel engine, the major breakdowns are occurring due failure cooling system $\&$ its components. This paper is presented the reliability analysis of cooling system of diesel engine using for compressor application, this work is using a time to failure data of cooling system and two parameter Weibull distribution analytical least square method \& Minitab 16.1R Software are used for parameter estimation, The results are shows reliability, Availability, Mean time between failure, Failure rate and Failure density. This is helpful for designing \& manufacturing of components and modification.
\end{abstract}

Keywords Cooling, Diesel Engine, Reliability \& Weibull Distribution

\section{Introduction}

Reliability is defined as the probability that a component or system will perform its required function for a given period of time when used under stated operating conditions [1]

A cooling system is constituted by a number of components and subsystems designed to achieve a common specific result with an acceptable level of reliability. The type of component failure and its frequency has a direct effect on the system's reliability. Thus it becomes very important to locate the critical components and analyze their reliability. Further-more, in many situations it is easier and less expensive to test components / subsystems rather than entire system.

The main parts of the engine cooling system are the radiator, pressure cap, hoses, thermostat, water pump, oil cooler, heat exchanger, fan, and fan belt \& pulley. The system is filled with coolant water. No matter where you live or how hot or cold the weather becomes, the mixture should be maintained the year around.

The two parameter Weibull distribution requires characteristic life $(\eta)$ and shape factor $(\beta)$ values. Beta $(\beta)$ determines the shape of the distribution. If $\beta$ is greater than 1 , the failure rate is increasing. If $\beta$ is less than 1 , the failure rate is decreasing. If $\beta$ is equal to 1 , the failure rate is constant. There are several ways to check whether data follows a Weibull distribution, the best choice is to use a Weibull analysis software product. If such a tool is not available, data can be manually plotted on a Weibull probability plot to determine if it follows a straight line. A straight line on the probability plot indicates that the data is following a Weibull distribution. Weibull shape parameter $\beta$ also indicates whether the failure rate is constant or increasing or decreasing if $\beta=1.0, \beta>1.0, \beta<1.0$ respectively. G.R Pasha \& et al.[2] presented the comprehensive analysis for complete failure data. Using the Weibull Distribution for failure data \&. Median rank regression (MRR) for data- fitting method is described and goodness-of-fit using correlation coefficient is applied. Sang-Jun Park \& et al. [3] demonstrate a reliability goal of the pump motor assembly within an affordable amount of time and in an economic way. Using the accelerated test (AT) and measured failure rate and MTTF. Y. Lei [4] estimating the Weibull distribution parameters, three methods namely maximum likelihood estimation method (MLE), method of moment (MOM) and least-squares regression method (LSM)] and evaluated on the basis of the mean square error (MSE) and sample size. Ahmad Mahir Razali \& et al. [5] compare between three methods for estimating the parameters of Weibull distributions. These methods are; moments, maximum likelihood and least squares 3-parameter Weibull distribution, using the means square error, MSE and total deviation, TD as measurement for the comparison between these methods and suggested the moments method is the best method for estimating the parameters of the 2-parameter and 3-parameter. Ghassan M. Tashtousha \& et al. [6] developed the statistical model and evaluate the effect of corrective and preventive maintenance schemes on car performance in the presence of system failure where the scheduling objective is to minimize schedule duration. Sunil Dutta \& et al. [7] carried out reliability analysis defense vehicle gear box assembly using the Weibull distribution. Aurelian Constantin \& et al. [9] presented the reliability analysis of automobile shock absorbers using the Weibull ++7 program. Yunn-Kuang Chu [8] examines the estimation comparison of two methods for Weibull parameters, one is the maximum likelihood method and the other is the least squares method. Based on sample 
root mean square errors, and suggested the least squares method is significantly compare to the maximum likelihood when the sample size is small. E. Suresh Kumar \& et al. [10] predicting the lifetime of the batteries using the Weibull distribution, the battery during operational life time and based on the sample data doing a Weibull analysis and suggesting the ways to improve the life time and the reliability of a battery. Ciprian - Mircea Nemeş [11] presents a comparative analysis of methods for estimating the Weibull parameters. These methods require historical wind speed data, collected over a certain time interval, to establish the parameters of the wind speed distribution for a particular location. M. Kaur \& et al. [12] formulate a stochastic model of an industrial process with an exponential distribution in order to check whether the results obtained actually exponential in nature. Results thus obtained for reliability of the process industry were analyzed for distribution fit using Minitab Software. Suresh Kumar \& et al. [13] two sets of photovoltaic modules were tested and estimation of reliability parameter using Weibull distribution.

Most of researchers are focus on reliability analysis using two parameter Weibull distributions and estimating parameters using analytical methods. Few researchers are estimating the parameters using computer software.

In this work estimating reliability of cooling system of diesel engine for compressor application \& its characteristics using two parameter Weibull distribution using analytical as well as computer software MINITAB16.1R.

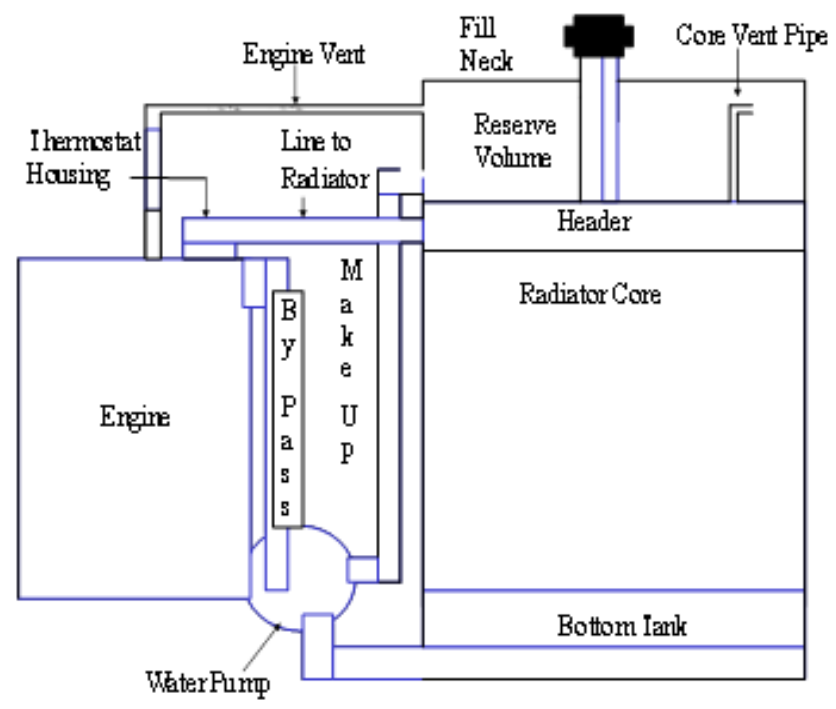

Figure 1. Layout of cooling system of diesel engine for compressor application

\section{Materials and Methods}

The study was held at company service station for thirty same Make \& Model diesel engines for compressor application .The failure of engine are consider only cooling system. First phase data collecting from the maintenance record of service station logbook period of two year is taken, Then data is sorted \& classified based on engine number, failure hour $\&$ failure subsystem. The cooling system failure data shown in Table 1

Table 1. Data on failure cooling system of Diesel Engine

\begin{tabular}{|c|c|}
\hline Engine No & Time of Failure(Hours) \\
\hline 1 & 1276 \\
\hline 2 & 720 \\
\hline 3 & 1135 \\
\hline 4 & 1854 \\
\hline 5 & 1687 \\
\hline 6 & 2570 \\
\hline 7 & 2440 \\
\hline 8 & 2547 \\
\hline 9 & 1100 \\
\hline 10 & 2117 \\
\hline 11 & 1876 \\
\hline 12 & 1633 \\
\hline 13 & 2646 \\
\hline 14 & 1556 \\
\hline 15 & 2470 \\
\hline 16 & 1895 \\
\hline 17 & 2607 \\
\hline 18 & 2480 \\
\hline 19 & 1250 \\
\hline 20 & 2628 \\
\hline 21 & 1668 \\
\hline 22 & 1267 \\
\hline 23 & 612 \\
\hline 24 & 886 \\
\hline 25 & 470 \\
\hline 26 & 2510 \\
\hline 27 & 2812 \\
\hline 28 & 2112 \\
\hline 29 & 401 \\
\hline 30 & 1907 \\
\hline
\end{tabular}

\subsection{Estimation of Mean Time Between Failure and Availability}

If a cooling system of diesel engine for compressor application is renewed by maintenance or repairs, so called as called repairable systems, the expected time of failure-free work E (T) known as the Mean Time Between Failures (MTBF) is calculated by equation [1]

$$
\mathrm{E}(\mathrm{T})=\mathrm{MTBF}=\frac{1}{n} \sum_{i=1}^{n} t \mathrm{i}
$$

Where:

$n-$ Number of engines $\quad t_{i}-$ the $i^{\text {th }}$ time of failure of engine

$$
\text { MTBF }=\frac{53132}{30}=1771.06 \text { Hours }
$$

Operational availability of a cooling system is the 
probability that the system, when used under specified conditions, will function satisfactorily at any point in time, whereas the observed time comprises the uptime and down time

$$
\text { Operational availability }=\text { Ao }=\frac{\text { Uptime }}{\text { Uptime+Downtime }}
$$

The operational availability of cooling system

$$
=\text { Ao }=\frac{53132}{53132+36868}=0.59
$$

\subsection{Determination of Failure Density Functions, Failure Rate and Reliability}

To determine the failure density function $\mathrm{f}(\mathrm{t})$ is equals the relation between the number of failures in the time interval and the total number of systems, failure rate function $\lambda(t)$ will equal the relation between the number of failures in the time interval and the number of systems which did not fail at the end of the time interval and The reliability function $\mathrm{R}(\mathrm{t})$ will equal the relation between the number of systems which did not fail at the end of the time interval and the total number of systems. [1]

Table2.Calculated values of empirical function

\begin{tabular}{|c|c|c|c|c|}
\hline $\begin{array}{c}\text { Time } \\
\text { interval } \\
\Delta \mathrm{t} \\
\text { (hour) }\end{array}$ & $\begin{array}{c}\text { Number of } \\
\text { failure }\end{array}$ & $\begin{array}{c}\text { Failure } \\
\text { density } \\
\mathrm{f}(\mathrm{t}) \mathrm{x} \\
{\left[10^{-4}\right]}\end{array}$ & $\begin{array}{c}\text { Failure } \\
\text { rate } \\
\lambda(\mathrm{t}) \mathrm{x} \\
{\left[10^{-4}\right]}\end{array}$ & $\begin{array}{c}\text { Reliability } \\
\mathrm{R}(\mathrm{t})\end{array}$ \\
\hline $000-500$ & 2 & 1.33 & 1.43 & 0.93 \\
\hline $501-1000$ & 3 & 2 & 2.4 & 0.83 \\
\hline $1001-1500$ & 5 & 3.33 & 5 & 0.60 \\
\hline $\begin{array}{c}1501- \\
2000\end{array}$ & 8 & 5.33 & 13.33 & 0.4 \\
\hline $2001-2500$ & 5 & 3.33 & 14.25 & 0.23 \\
\hline $2501-3000$ & 7 & 4.66 & 0 & 0 \\
\hline
\end{tabular}

The figure $2.3 \& 4$ show empirical functions of failure, density, failure rate and reliability function respectively.

\section{Failure density}

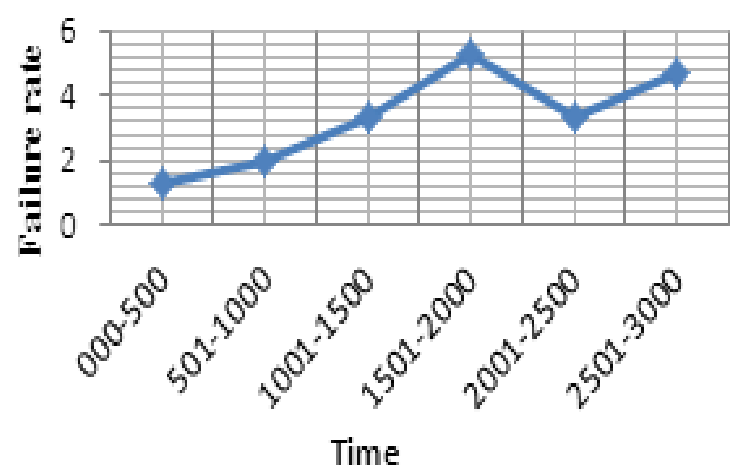

Figure 2. Failure density $V s$ Time

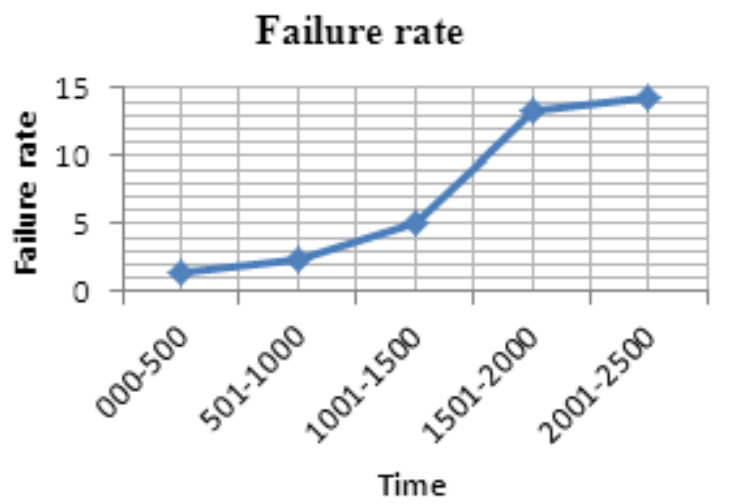

Figure 3. Failure rate $V s$ Time

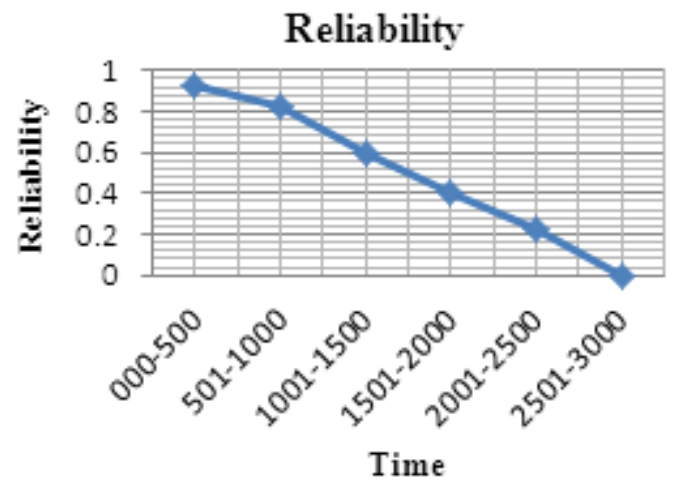

Figure 4. Reliability $V_{S}$ Time

\section{Weibull Distribution}

The Weibull distribution most frequently provides the best fit of life data. Beta $(\beta) \&$ Scale $(\eta)$ are the two crucial parameters of Weibull line. The slope of the line, $\beta$ is principally significant and may provide a trace to the physics of failure. The characteristic life $\eta$ is the typical time to failure in Weibull analysis (Abernethy Robert, 2002). The slope $\beta$ also indicates which class of failures is present. $\beta<$ 1.0 indicates infant mortality, $\beta=1.0$ means random failures (independent of age) $\& \beta>1.0$ indicates wear out failures .

The effect of different values of shape parameter $\beta$, on the shape of the pdf (while keeping $\eta$ constant). The shape of the pdf can take on a variety of forms based on the value of $\beta$. Weibull probability plot specifies the Weibull shape parameter. it is also known as the slope.

The reliability function $\operatorname{Rv}(\mathrm{t})$ assumes the following configuration

$$
\begin{gathered}
\operatorname{Rv}(\mathrm{t})=e^{-\left(\frac{t}{\eta}\right)^{\beta}} \\
\lambda v(\mathrm{t})=\frac{\beta}{\eta} \times\left(\frac{t}{\eta}\right)^{\beta-1}
\end{gathered}
$$

Where

$\beta$ - Shape parameter

$\eta$ - Scale parameter 


\subsection{Least Squares Method:}

For the estimation of Weibull parameters, the least-squares method (LSM) is extensively used in engineering problems. The method provides a linear relation between the two parameters having as start point the twice logarithms of Weibull cumulative distribution function, as follows:

When applying the mathematical operation of logarithm (natural logarithm $\mathrm{ln}$ ), the reliability function may also be written as.

$$
Y=\beta X+C
$$

Where:

$$
\begin{gathered}
\mathrm{Y}=\ln [-\ln \operatorname{Rv}(\mathrm{t})] \\
\mathrm{X}=\ln \mathrm{t} \\
\mathrm{C}=-\beta \times \ln \eta \\
\beta=\frac{-2.66-0.37}{6.21-7.82}=1.88 \\
\mathrm{C}=-2.99-1.88 \times 6.21=-14.66 \\
\eta=e^{-c / \beta}=\mathrm{e}^{-(-14.66 / 1.88)}=\mathrm{e}^{7.79}=2416.31
\end{gathered}
$$

Reliability of the Weibull distribution is

$\mathrm{R}(\mathrm{t})=e^{-\left(\frac{t}{\eta}\right)^{\beta}}=\mathrm{e}-(2417.19 / 2416.31)^{1.88}=0.37$

Reliability as per actual data $=\mathrm{R}(\mathrm{t}) \quad=0.66+0.4 / 2=0.53$

Expected time to failure $=\mathrm{E}(\mathrm{T})=\gamma+\eta \times \Gamma(1 / \beta+1)$

$$
\begin{aligned}
\mathrm{E}(\mathrm{T}) & =0+2416.31 \times \Gamma(1 / 1.88+1) \\
& =2417.19 \text { Hours }
\end{aligned}
$$

Failure rate $=\lambda v(t)=\frac{\beta}{\eta} \times\left(\frac{t}{\eta}\right)^{\beta-1}$

$$
\begin{aligned}
& =1.88 / 2416.31 \times(2417.19 / 2416.31)^{1.88-1} \\
& =7.78 \times 10^{-4} \quad \text { Failure /hours }
\end{aligned}
$$

Failure rate as per actual data $=\lambda(\mathrm{t})$

$=5 \times 10^{-4}+13.33 \times 10^{-4} / 2=9.16 \times 10^{-4}$ Failures / Hour

Failure density $=\lambda(\mathrm{t}) \times \mathrm{R}(\mathrm{t})=7.78 \times 10^{-4} \times 0.37$

$$
=2.878 \times 10^{-4}
$$

Failure density as per actual data $=\lambda(\mathrm{t}) \times \mathrm{R}(\mathrm{t})$

$$
=9.16 \times 10^{-4} \times 0.53=4.85 \times 10^{-4}
$$

\subsection{Parameters Estimation Using Minitab}

Weibull parameters estimation using the Minitab 16.1R software using the failure data of cooling system of diesel engine for compressor application and determine the reliability ,failure rate $\&$ failure rate.

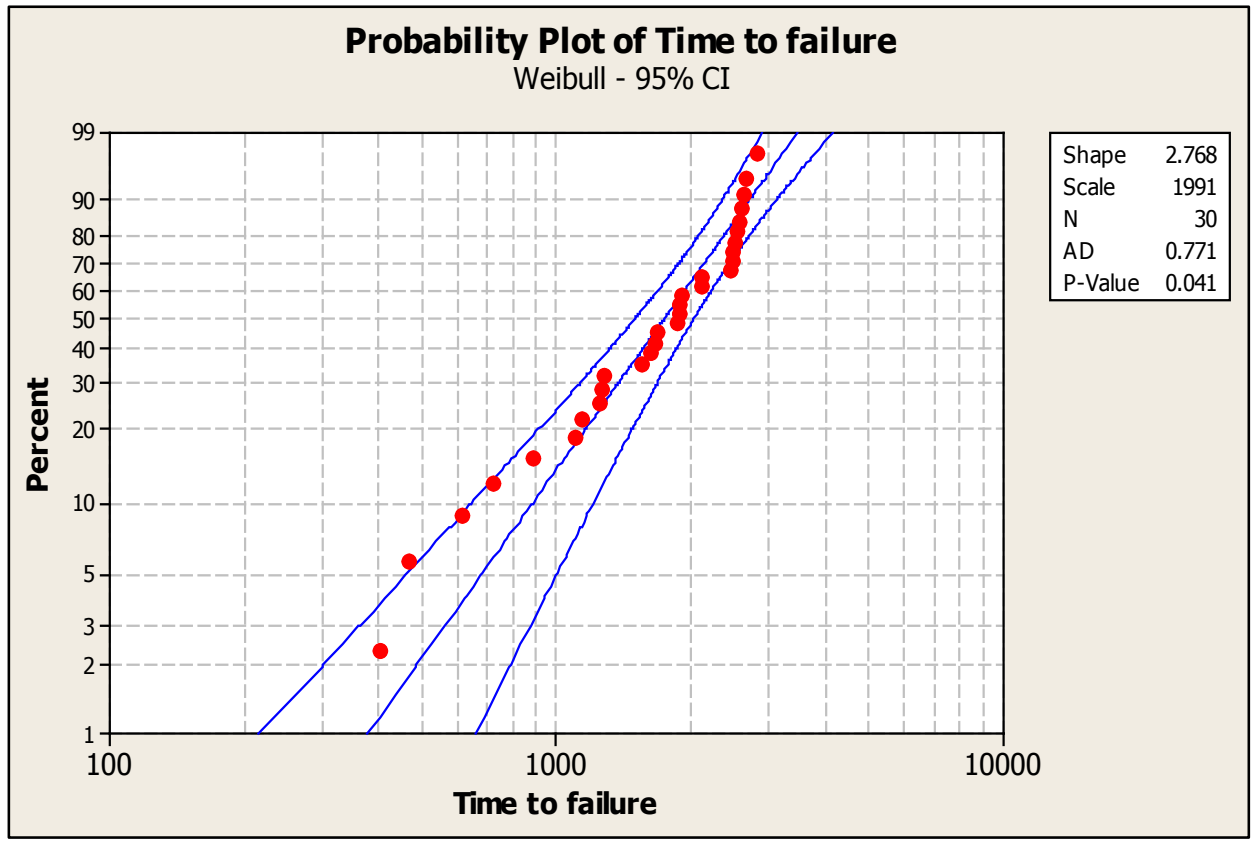

Figure 5. Weibull Probability plot 


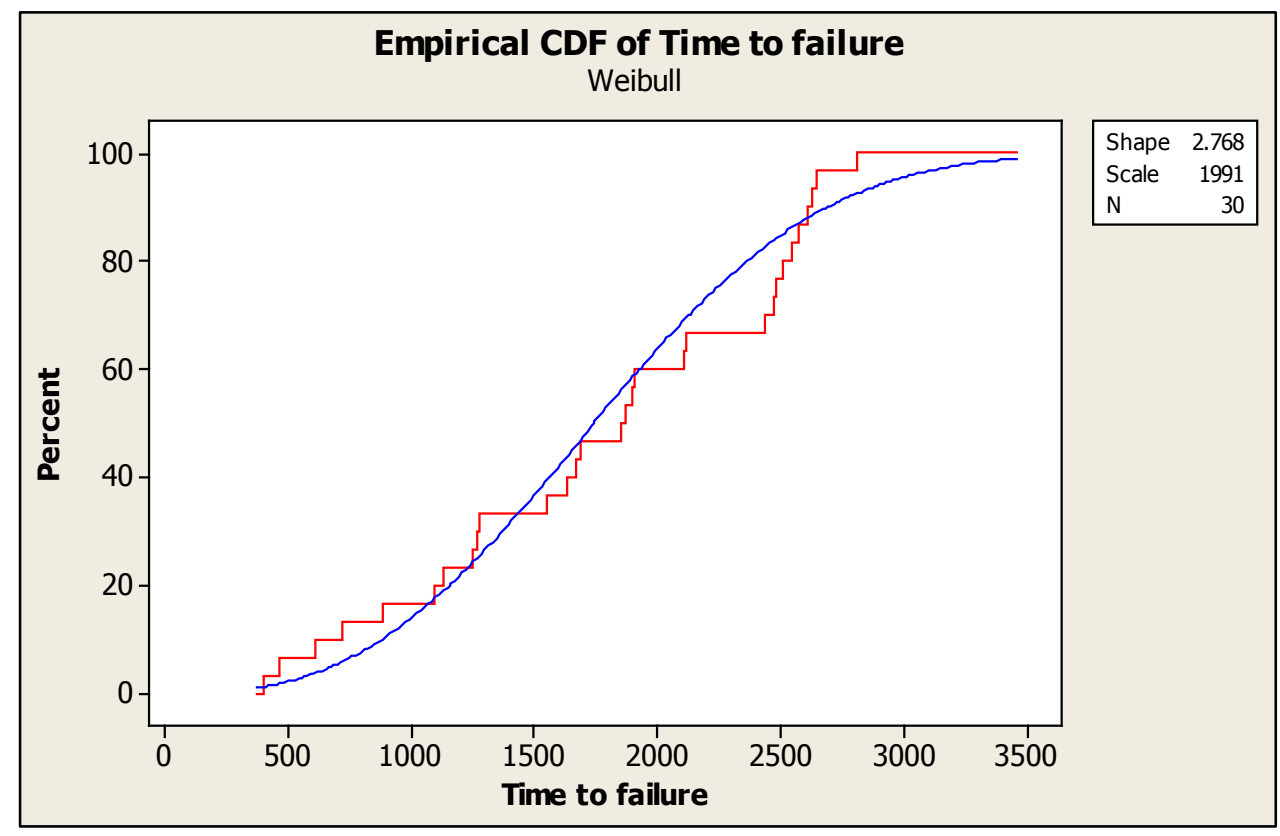

Figure 6. Cummulative density function

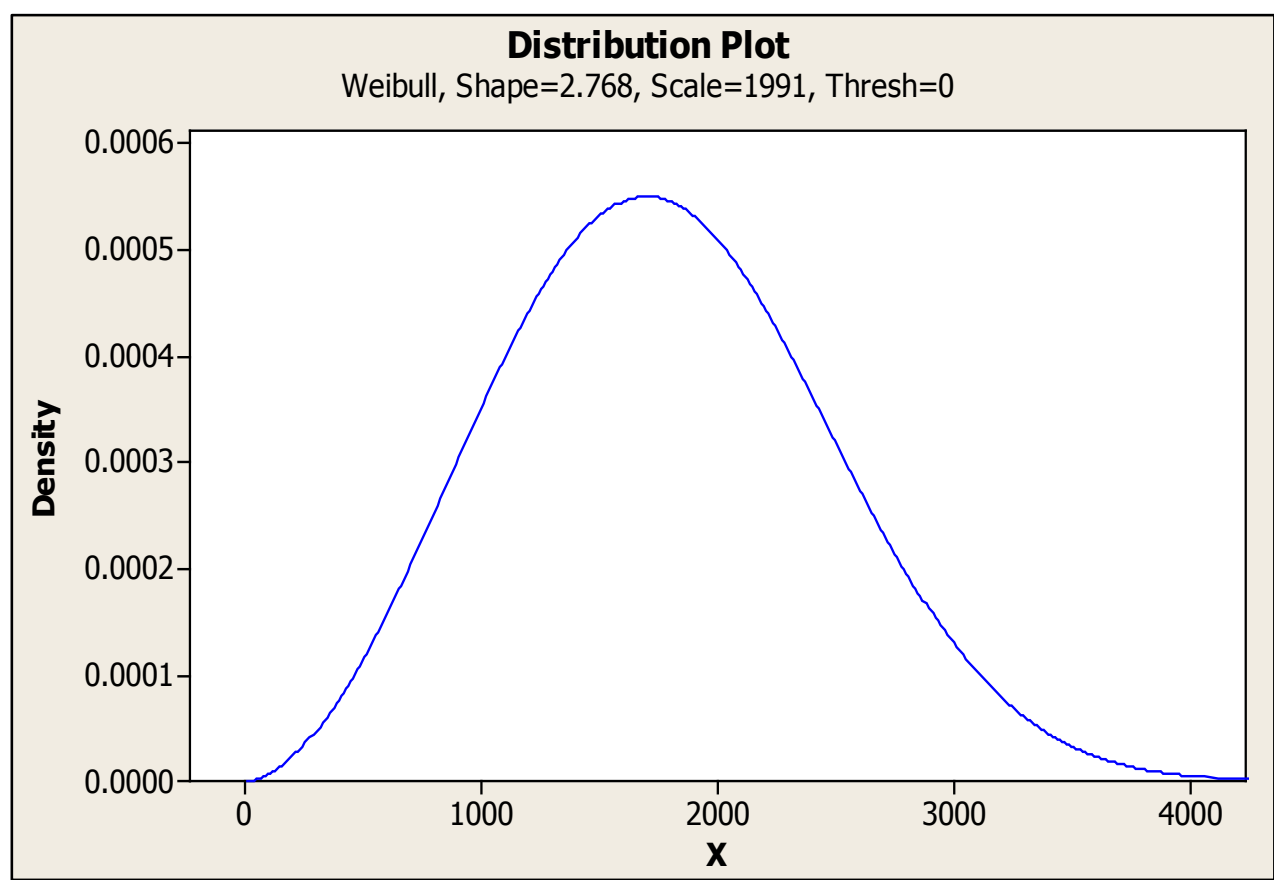

Figure 7. Distribution plot

Refer Fig. 5 shape parameter $(\beta)=2.768 \&$ scale parameter $(\eta)=1991$ Hours

To determine the reliability, failure rate \& failure density Reliability R (t) of the Weibull distribution.

$$
=\mathrm{R}(\mathrm{t})=e^{-\left(\frac{t}{\eta}\right)^{\beta}}
$$

Expected time to failure $=\mathrm{E}(\mathrm{T})=\gamma+\eta \times \Gamma(1 / \beta+1)$

$$
=0+1991 \times \Gamma(1 / 2.768+1)
$$

$=1991 \times \Gamma(1.36)=1991 \times 0.8901=1772.19$ Hours

$$
\mathrm{R}(\mathrm{t})=e^{-\left(\frac{1772.19}{1991}\right)^{2.768}}=0.48
$$

Failure rate $=\lambda v(t)=\frac{\beta}{\eta} \times\left(\frac{t}{\eta}\right)^{\beta-1}$

$$
\begin{aligned}
& =2.768 / 1991 \times(1772.19 / 1991)^{1.768} \\
& =11.31 \times 10^{-4} \text { Failure } / \text { Hours }
\end{aligned}
$$

Failure density $=\frac{\beta}{\eta} \times\left(\frac{t}{\eta}\right)^{\beta-1} \times e^{-\left(\frac{t}{\eta}\right)^{\beta}}$

$$
\begin{aligned}
& =0.48 \times 11.31 \times 10^{-4} \\
& =5.428 \times 10^{-4}
\end{aligned}
$$

If a cooling system of diesel engine for compressor application is renewed by maintenance or repairs, so called as called repairable systems, the expected time of failure-free work E (T) known as the Mean time between failures (MTBF) 
is calculated by equation [1]

Table 3. Results

\begin{tabular}{|c|c|c|c|c|}
\hline Data & $\begin{array}{c}\text { Time of } \\
\text { failure (Hour) }\end{array}$ & $\begin{array}{c}\text { Reliability } \\
\mathrm{R}(\mathrm{t})\end{array}$ & $\begin{array}{c}\text { Failure rate } \\
\lambda(\mathrm{t}) \\
\text { failure/ Hrs } \\
\times 10^{-4}\end{array}$ & $\begin{array}{c}\text { Failure } \\
\text { density } \\
\mathrm{f}(\mathrm{t}) \\
\times 10^{-4}\end{array}$ \\
\hline $\begin{array}{c}\text { Actual } \\
\text { data }\end{array}$ & $\begin{array}{c}\mathrm{MTBF}= \\
1771.06\end{array}$ & 0.53 & 9.16 & 4.85 \\
\hline Weibull & $\begin{array}{c}\mathrm{E}(\mathrm{T}) \\
=2417.19\end{array}$ & 0.37 & 7.78 & 2.878 \\
\hline Minitab & $\begin{array}{c}\mathrm{E}(\mathrm{T})= \\
1772.35\end{array}$ & 0.48 & 11.31 & 5.428 \\
\hline
\end{tabular}

\section{Result \& Discussion}

For constant failure rate value, i.e. that the failure rate is not time dependent In case of constant failure rate, equation is valid:

$$
\lambda=1 / \mathrm{MTBF}=1 / 1771.06=5.646 \times 10^{-4}
$$

The obtained failure rate value is significantly lower than the empirical one and the one calculated on the basis of the Weibull distribution. In the process of estimating certain technical system reliability it is common to assume that the failure rate is constant.

In that case of random failures are present and the failure rate is not time dependent. Reliability cooling system shows continuously rising failure rate function and the fact that the reliability of the above mentioned system can be well approximated by the Weibull distribution. Despite its complexity, the Weibull distribution is commonly used when estimating reliability. It includes decreasing, constant, and increasing failure rate functions.

The reasons for the cooling system failure vary from overloaded engine and fatigue of materials to wear and corrosion.

\section{Conclusions}

The conducted research regarding the reliability of cooling system diesel engine for compressor application are showed that one cannot take for granted the assumption about constant failure rate $\lambda(t)=$ constant. Therefore, empirical approximation of functions was taken and it showed that the Weibull distribution with parameters $\beta=1.88$ and $\eta=$ 2416.31Hours approximates well the reliability of the cooling system and that the expected time of failure-free function $\mathrm{E}(\mathrm{T})=2417.19$ hours.

Cooling system has an increasing rate of failure, and that failure causes may be different in nature: from overloading the engine and fatigue of material, to wear and corrosion, it was necessary to determine the individual failure rates of cooling system subsystems (parts) and their contribution to overall reliability and failure rate.

\section{Acknowledgments}

The authors are deeply grateful for helps of General Managers Mr. Yuvraj Lavhale and employees of Trinity Mahalasa Durga sales \& services, Aurangabad during field studies. We also like to thanks Dr. M.D. Jaybhaye, Associate professor in Production Engineering Department college of Engineering pune \& Dr. S.K Basu, Professor Emeritus, College of Engineering Pune.

\section{REFERENCES}

[1] Ebeling C. E., An Introduction to Reliability and Maintainability Engineering, McGraw-Hill (Asia) Co. 1997

[2] G.R Pasha, M. Shuaib Khan, Ahmed Hesham Pasha, Empirical Analysis of the Weibull Distribution for Failure Data, Journal of Statistics Vol: 13, No.1 33-45, 2006.

[3] Sang-Jun Park, Sang-Deuk Park, Kwang-Suck Kim, Ji-Hyun C, Reliability evaluation for the pump assembly using an accelerated test, International Journal of Pressure Vessels and Piping 83 283-286, 2006.

[4] Y. Lei, (2008), Evaluation of three methods for estimating the Weibull distribution parameters of Chinese pine (Pinus tabulaeformis), Journal of Forest Science, 54, 2008 (12): 566571,2008

[5] Ahmad Mahir Razali, Ali A. Salih and Asaad A. Mahdi, Estimation Accuracy of Weibull Distribution Parameters, Journal of Applied Sciences Research 5(7): 790-795, 2009.

[6] Ghassan M. Tashtousha, Khalid K. Tashtoush, Mutaz A. Al-Muhtaseba, Ahmad T. Mayyasb, Reliability Analysis of Car Maintenance Scheduling and Performance, Jordan Journal of Mechanical and Industrial Engineering_Vol. 4, No. 3, 388-393, 2010.

[7] Sunil Dutta, Dinesh Kumar and Pradeep Kumar, Reliability analysis of defense vehicles gearbox assembly under preventive maintenance, Indian Journal of Science and Technology Vol. 3, No. 3, 328-331, 2010.

[8] Yunn-Kuang Chu and Jau-Chuan Ke, Computation approaches for parameter estimation of Weibull distribution, Mathematical and Computational Applications, Vol. 17, No. 1, 39-47, 2012.

[9] Aurelian Constantin \& Andrei Dragos Mircea, Research regarding the reliability of the Shock absorbers of a number of automobiles using weibull distribution, U.P.B. Sci. Bull., Series D, Vol. 73, Iss. 3, 109-119, 2011.

[10] E. Suresh Kumar, Dr. Bijan, Improvement of life time and reliability of battery, International Journal of Engineering Science \& Advanced Technology, Volume-2, Issue-5, 1210-1217, 2012.

[11] Ciprian-Mircea Nemeş Statistical Analysis of Wind Speed Profile:A Case Study from Iasi Region, Romania International Journal of Energy Engineering, Vol. 3 Iss. 6, 261-268, 2013.

[12] M. Kaur, A. K. Lal and S. S. Bhatia, Reliability distribution of an Industrial Process, International Journal of Research in Advent Technology, Volume 1, Issue 5, pp 587-592, 2013.

[13] Suresh Kumar and Bijan Sarkar, Design For Reliability With Weibull Analysis For Photovoltaic Modules, International Journal of Current Engineering and Technology, Vol.3, No.1, pp 129-135, 2013. 